\title{
O ESTUDO DAS ONDAS ELETROMAGNÉTICAS A PARTIR DO ENFOQUE CTS: UMA POSSIBILIDADE PARA O ENSINO DE FÍSICA NO ENSINO MÉDIO
}

\section{THE STUDY OF ELECTROMAGNETIC WAVES FROM THE CTS APPROACH: A POSSIBILITY FOR PHYSICAL EDUCATION IN MIDDLE SCHOOL}

\author{
Ederson Carlos Gomes \\ Doutorando em Educação para Ciência e a Matemática da Universidade Estadual de Maringá - \\ edersoncgomes@gmail.com \\ Michel Corci Batista \\ Programa de Pós Graduação em Ensino de Física da Universidade Tecnológica Federal do \\ Paraná - CM - michel@utfpr.edu.br \\ Polonia Altoé Fusinato \\ Programa de Pós Graduação em Educação para Ciência e a Matemática da Universidade \\ Estadual de Maringá - altoepoly@gmail.com
}

\begin{abstract}
Resumo
O presente artigo refere-se a uma investigação com estudantes da terceira série do Ensino Médio, na qual foi realizada uma sequência didática para estudo de ondas eletromagnéticas. A sequência didática foi estruturada a partir perspectiva Ciência, Tecnologia e Sociedade (CTS), a fim de promover um ambiente de aprendizagem diferente do convencional, no qual os alunos pudessem interagir entre si e ampliar sua visão sobre a ciência, sobre tecnologia e principalmente sobre suas implicações na sociedade. Foram realizados seis encontros em uma turma de treze alunos em uma escola pública no município de Farol, PR. A coleta de dados ocorreu por meio de questões problema respondidas pelos alunos e notas de campo do pesquisador. Os dados foram analisados seguindo os pressupostos da pesquisa qualitativa e os resultados foram organizados em três categorias definidas pelos aspectos abordados nas atividades e pelo conhecimento físico envolvido. Os resultados evidenciam a importância e a potencialidade das atividades desenvolvidas, destacando-se quatro aspectos: a motivação dos alunos para o cumprimento das atividades propostas, a organização dos trabalhos nos pequenos grupos, uma predisposição para estudar os conteúdos de física e principalmente o estabelecimento de relações da física com aplicações tecnológicas. Podemos aqui inferir, que a única mudança no contexto escolar nesse período foi a postura do professor com relação à turma, nessa proposta a postura do professor foi de facilitador e mediador dos debates.
\end{abstract}

Palavras-chave: Ensino de Física. Sequência Didática. Ciência Tecnologia e Sociedade (CTS). Ondas Eletromagnéticas.

\section{Abstract}

The present article refers to an investigation with students of the third grade of High School, in which a didactic sequence was carried out to study electromagnetic waves. The didactic sequence was structured from the perspective of Science, Technology and Society (CTS), in order to promote a learning environment different from conventional, in 
which students could interact with each other and broaden their vision about science, technology and especially about Implications in society. Six meetings were held in a class of thirteen students in a public school in the municipality of Farol, PR. Data collection occurred through problem questions answered by the students and field notes of the researcher. The data were analyzed according to the qualitative research assumptions and the results were organized into three categories defined by the aspects covered in the activities and by the physical knowledge involved. The results highlight the importance and potential of the activities developed, highlighting four aspects: the motivation of the students to carry out the proposed activities, the organization of the work in the small groups, a predisposition to study the contents of physics and especially the establishment of Relations of physics with technological applications. We can infer here that the only change in the school context in this period was the teacher's attitude towards the class, in this proposal the teacher's posture was the facilitator and mediator of the debates.

Keywords: Teaching Physics. Following teaching. Science Technology and Society (CTS). Electromagnetic waves.

\section{Introdução}

Os jovens ao ingressarem no Ensino Médio, chegam estimulados pela mudança de nível de ensino, de acordo Bonadiman e Nonemachr (2007), eles chegam motivados para compreender novos horizontes científicos, tendo uma grande expectativa em relação a disciplina de física. Porém, sabe-se que entre outros fatores, o pouco tempo de estudo (duas aulas por semana nas instituições públicas de ensino), é insuficiente para que os alunos possam se apropriar dos conceitos físicos e compreendê-los em toda sua complexidade.

É bastante comum, que grande parte dos estudantes e professores considere a disciplina física, como uma extensão da matemática, tornando seu entendimento mais difícil, ou no mínimo menos atrativo, constituindo-se um problema de influência negativa para o aprendizado da mesma. No entanto, esse é um paradigma que deve ser superado, pois em pleno século $\mathrm{XXI}$, os educandos precisam de muito mais que emanherados de "fórmulas", visto que atualmente tem sido exigido que os indivíduos se aperfeiçoem continuamente em prol de seu desenvolvimento.

Devemos lembrar que "Ensinar não é transmitir conhecimentos, mas criar as possibilidades para a sua produção ou a sua construção" (FREIRE, 1992 p. 25). Neste sentido, o professor sendo o mediador do processo de ensino e aprendizagem, deve trabalhar com os conhecimentos trazidos pelos alunos, se atentando em discutir na sala de aula, problemas do cotidiano dos alunos, mas que estejam relacionados e contextualizados com as informações que o mundo thes apresenta diariamente. Assim, os educadores devem investigar e propor recursos que facilitem a compreensão de conceitos físicos e a presença destes no cotidiano dos aprendizes, contribuindo para o processo de ensino e aprendizagem e a construção do conhecimento individual do cidadão.

Nesse sentido, devemos recordar que o desenvolvimento científico influência diretamente a vida de todos os seres humanos, não sendo possível desvincular a perspectiva de Ciência, Tecnologia e Sociedade (CTS) deste contexto. Isso ocorre em 
vários setores da sociedade (medicina, agricultura, comunicação, segurança, etc.), que se apropriam de muitos conhecimentos do campo da física para proporcionar uma boa qualidade de vida, como no caso da medicina, por exemplo, que os utilizam para a realização de exames preventivos, diagnósticos e tratamentos de saúde, sendo esses de grande importância para os seres humanos.

\title{
Fundamentação teórica
}

As discussões sobre a aproximação entre os diferentes níveis de ensino de física ofertado nas escolas brasileiras e a realidade dos educandos não é nova e, apesar das pesquisas sobre o ensino de física no Brasil terem avançado significativamente nas últimas décadas "o ensino de física real ministrado na maioria das escolas, ainda se resume a um emaranhado de fórmulas” (SENRA, 2011, p. 9). Nesse sentido, Rosa \& Rosa se manifestam dizendo que:

\begin{abstract}
"entende-se que o ensino de Ciências, e, neste caso específico, o de física, precisa ser redimensionado, iniciando-se por uma real e efetiva proposta curricular [...], ultrapassando a visão de disciplina vinculada à memorização de nomenclaturas e as listas intermináveis de fórmulas" (ROSA; ROSA, 2012, p. 1).
\end{abstract}

Corroborando com a ideia, Sanches e Neves (2011) afirmam que a escola não está preparada para propiciar ao estudante o entendimento para uma nova construção de mundo, quanto mais um ensino de ciência que possa ser utilizado em sua vida cotidiana. Esses autores afirmam que pensar no currículo de Ensino Médio é a peça chave para tornar o aluno um cidadão pleno, consciente e participativo. Porém, verificamos que:

A situação, hoje, na educação pública brasileira demonstra que os professores possuem formação deficiente, consequentemente, os alunos não consolidam uma base suficiente para a construção não somente do conhecimento da física, mas do conhecimento como uma trama interdisciplinar e doadora de significados ao mundo que os rodeia" (SANCHES; NEVES, 2011, p. 9).

Como uma possibilidade de minimizar tais problemas, por volta de 1950 surgiu um movimento que buscava aproximar a escola e sociedade em uma perspectiva CTS Ciência, Tecnologia e Sociedade, devido ao contexto social do mundo naquele período. Segundo Santos e Mortimer (2000) após a Segunda Guerra Mundial, os trabalhos curriculares em CTS surgiram devido à necessidade de formar o cidadão em ciência $e$ tecnologia, o que não estava sendo satisfatoriamente alcançado pelo ensino convencional de ciências.

De acordo com Resquette (2013), o movimento CTS foi iniciado perante a constatação de que o desenvolvimento científico e tecnológico estava atrelado a degradação ambiental, pelo uso de fertilizantes químicos e pesticidas para um aumento significativo da produção de alimentos, mas por outro lado, alguns anos depois foi feito um alerta sobre o uso indiscriminado desses produtos agrícolas e suas consequências danosas ao meio ambiente e aos seres humanos. Esse contexto promoveu um intenso 
debate entre representantes da indústria química, políticos, cientistas e ativistas, chegando ao ponto destes últimos serem acusados de serem contra o progresso mundial.

A partir de situações como a citada anteriormente, os países industrializados de todo o mundo passaram a incorporar a tendência CTS nos seus currículos escolares, enfatizando a alfabetização científica e tecnológica como parte essencial na formação de todos os cidadãos (RESQUETTE, 2013). Pinheiro, Silveira e Bazzo (2007, p. 72) afirmam que "Esse movimento tem se manifestado desde 1970, tendo sido base para construir currículo em vários países, em especial os de ciências, dando prioridade a uma alfabetização em ciência e tecnologia interligada ao contexto social".

No Brasil os primeiros indicativos sobre CTS surgiram a partir do ano de 1970 (ROSA; ROSA, 2012), pois a ciência passou a ser vista como um dos fatores essenciais para o desenvolvimento do país, isso porque o mesmo naquele momento estava em um período intenso de industrialização. Neste cenário, apareceram às primeiras preocupações em relação ao meio ambiente e de acordo com Santos (2007) foi a partir das mesmas que surgiram as proposições iniciais de inclusão de CTS no currículo de ciências brasileiro.

Neste sentido:

"[...] o ensino de ciências, apoiado nos grandes projetos traduzidos e/ou elaborados no país, nos anos 60 e 70, em que pesam os avanços em conteúdos e metodologias, propunha-se mais a identificar e a seduzir os alunos para as carreiras científicas e tecnológicas do que para induzir discussões de fundo sobre CTS" (ANGOTTI; AUTH, 2001, p. 7).

Percebe-se que apesar de surgirem algumas preocupações a respeito do ensino de ciências em relação aos temas ambientais, ainda prevalecia um ensino propedêutico, que não favorecia o desenvolvimento de uma consciência crítica no aluno, levando-o a pensar em sua realidade circundante em termos de CTS, ainda mais naquele momento em que se visava formar mão de obra barata pela educação profissional técnica.

De acordo com Resquette (2013) ainda tiveram grande peso, fatores como a formação deficitária de professores, falta de apoio financeiro às escolas e aumento da diversidade entre os estudantes, que se somaram para que o ensino de ciências tivesse baixa aceitação e pouca efetividade em torno desta perspectiva.

Por volta de 1980, "o ensino de ciências tomou uma dimensão de produção do conhecimento voltada para os avanços tecnológicos” (ROSA; ROSA, 2012, p. 8), e devido ao vínculo entre ciência e tecnologia, foi iniciada a discussão em torno dos benefícios da associação das mesmas para os seres humanos e a sociedade. Então, questões que faziam parte do meio social foram elencadas e discutidas, de modo que a sua solução apontasse para uma necessidade de melhora do ensino de ciências e sua aproximação aos problemas do meio social no qual o indivíduo estava inserido. Em relação ao Brasil, segundo os mesmos, o ensino de ciências não conseguiu atingir os níveis desejados em CTS, mantendo-se tradicional e desconectado das concepções modernas de educação daquele momento. 
Auller (2002) aponta uma série de fatores que influenciaram o ensino de CTS no Brasil, como: a desvinculação da investigação científica-tecnológica do setor produtivoindustrial, a não definição de uma política científico-tecnológica, obstáculos estruturais, concentração de renda, a globalização, a abertura neoliberal e obstáculo institucional. Nesse contexto o enfoque CTS foi inserido tardiamente e constatado no currículo escolar brasileiro a partir das reformas curriculares da década de 1990 (RESQUETTE, 2013), pois as discussões em torno do mesmo influenciaram a reformulação dos documentos que regulamentariam a educação brasileira a partir daquele período.

\begin{abstract}
"Até então a orientação do ensino de Ciências era bastante tradicional, limitando-se à transmissão de conteúdos através de aulas quase sempre expositivas e ao uso do livro didático como único recurso em sala de aula. A ênfase das atividades ministradas pelo professor recaía na resolução excessiva de exercícios memorísticos e algébricos, desvinculados da realidade do aluno" (RESQUETTE, 2013, p. 40).
\end{abstract}

Essas estruturas curriculares tradicionais (ANGONTTI; AUTH, 2001) representavam a reprodução de certos valores historicamente determinados, como a cultura da passividade, que reforçava uma concepção de sociedade com uma nítida relação de exploração e exclusão.

De acordo com Resquette (2013) a constatação do enfoque CTS se deu no texto dos Parâmetros Curriculares Nacionais (PCNs) para o Ensino Médio, que foi publicado em 1998, trazendo em seu corpo às competências que deviam ser desenvolvidas no ensino de física e nas demais disciplinas. Santos e Mortimer (2000) afirmam que a reforma curricular do Ensino Médio, proposta no final da década de 1990 incorporou, em seus objetivos e fundamentos, elementos dos currículos com ênfase em CTS.

Em relação à Diretriz Curricular de Física do Estado do Paraná, constatamos que ela propõe um ensino que esteja bastante próximo à realidade do educando e em alguns momentos ela apresenta muitos pontos comuns com os objetivos propostos nos PCNs, entretanto não faz menção alguma sobre o enfoque CTS, reforçando os estudos de Resquette (2013).

Nesse sentido, Brasil (2014) defende a inserção do enfoque CTS em sala de aula e que o mesmo seja desenvolvido a partir de uma sequência bem organizada e planejada. $\mathrm{Na}$ figura 1 a seguir, apresentamos um esquema simplificado de implementação do enfoque CTS para alunos do Ensino Médio e que tem sido defendido por esse mesmo autor. 


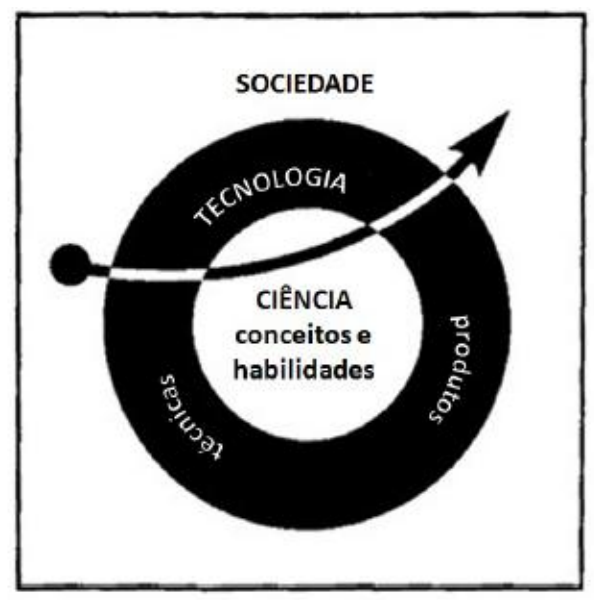

Figura 1: Sequência para o ensino de Ciências CTS

Fonte: Brasil (2014, p.25) apud (AIKENHEAD, 1994, p.57).

Brasil (2014) afirma que a origem da seta na área branca da figura 1, representa a Sociedade e indica que ao trabalhar com o enfoque CTS, devemos partir de um problema social levantado, que envolva as necessidades ou controvérsias que envolva a comunidade, na qual se atribui algo as ciências da natureza (Biologia, Física e Química). A coroa circular preta representa a Tecnologia, e sugere, de acordo com Brasil (2014), que para compreender questões sociais é preciso inserir elementos da mesma e suas consequências quando utilizadas inadequadamente.

O círculo central branco da figura 1 representa a ciência com seus conceitos científicos específicos que ajudam 0 aluno a compreender as dimensões sociais e tecnologias do problema (BRASIL, 2014). A seta, referente à mesma figura termina novamente no domínio da sociedade, consistindo na retomada do problema inicial.

Diante do exposto é solicitado ao estudante tomar decisões, discutindo inclusive politicas que devam ser usadas para determinadas tecnologias e, acreditamos que 0 ensino de física na perspectiva CTS deve contribuir para a construção de uma visão voltada para a formação de um cidadão contemporâneo, atuante e solidário, com instrumentos para compreender, intervir e participar na realidade. Então:

"[...] para que o ensino de Física contribua na participação do aluno na sociedade de forma mais efetiva, ela não deve ter como objetivo apenas a aprendizagem de fatos, teorias e leis, pois é preciso proporcionar ao aprendiz uma compreensão crítica da natureza da ciência e da tecnologia" (SENRA, 2011, p. 19).

Neste sentido, Pinheiro, Silveira e Bazzo (2007), afirmam que é preciso buscar o ensino que propicie condições para o desenvolvimento de habilidades por meio de estratégias muito bem estruturadas e organizadas, levando em conta os conhecimentos prévios dos alunos, que podem ser acessados mediante a contextualização dos temas sociais a partir do problema que se apresenta, mesmo que sejam discutidos antes do ponto de vista do conhecimento, sejam eles, matemáticos, físicos, químicos, biológicos, etc. 
Pinheiro, Silveira e Bazzo (2007), ressaltam ainda que a utilização do enfoque CTS no Ensino Médio não pode ser reduzido a mudanças organizativas e de conteúdos curriculares. Deve haver mudança na metodologia educativa, com objetivo de promover uma atitude criativa e crítica, na qual é necessária uma nova postura perante os conteúdos a serem estudados, pois, a pretensão do ensino com enfoque CTS é maximizar a participação dos alunos e minimizar a participação do professor.

Para isso Azevedo et. al. (2013) afirma que os professores necessitam de uma formação que proporcione condições de desenvolver saberes, com significado científico, social e cultural para atender as diferentes realidades, interesses e formas de aprender, para que possa proporcionar ao aluno a construção de atitudes e valores para agir no mundo com uma visão mais responsável, cidadã e democrática.

Pinheiro, Silveira e Bazzo (2007), dizem que o professor é o grande articulador no ensino com enfoque CTS, pois, é ele quem deve garantir a mobilização dos saberes para o desenvolvimento do processo e a realização de projetos. Portanto, deve proporcionar ao aluno, meios que estabeleçam conexões entre o conhecimento adquirido e o pretendido, com o objetivo de resolver situações problema que estejam de acordo com as condições intelectuais, emocionais e contextuais dos mesmos.

Para que isso seja possível:

"[...] precisamos de uma imagem de ciência e tecnologia que possa trazer
à tona a dimensão social do desenvolvimento científico-tecnológico,
entendido como produto resultante de fatores culturais, políticos e
econômico. Seu contexto histórico deve ser analisado e considerado como
uma realidade cultural que contribui de forma decisiva para mudanças
sociais, cujas manifestações se expressam na relação do homem consigo
mesmo e com os outros" (PINHEIRO; SILVEIRA; BAZZO. 2007, p. 73).

Neste sentido, as aulas de física devem estar abertas ao debate e a discussão sobre o papel e as influências exercidas pelo conhecimento científico na sociedade, enfatizando a busca da emancipação cultural do educando, conduzindo-o a ser sujeito ativo na construção da sua própria história.

Diante do exposto "É preciso estimular o aluno a desenvolver adaptabilidade e flexibilidade, formando-o como pessoa que tome decisões humanas na determinação da sobrevivência e da vida na sociedade futura" (PINHEIRO; SILVEIRA; BAZZO, 2007, p.79). Concordando com esses autores, acreditamos que a abordagem CTS em sala de aula em uma perspectiva crítica ajudará a ampliar o olhar sobre qual é o papel da ciência e da tecnologia na sociedade, proporcionando discussões sobre questões econômicas, politicas, sociais, culturais, éticas e ambientais, contribuindo para a autoformação do aluno e estimulando-o a assumir a sua condição humana e incentivando-o a tornar-se um cidadão em uma democracia onde ele deverá ser solidário, participativo e responsável pelas suas atitudes. 


\section{Metodologia}

O presente trabalho foi desenvolvido no ano de 2016 em um colégio público localizado no município de Farol (região centro oeste do Estado do Paraná), com uma turma de 13 alunos (04 masculinos e 09 femininos) da terceira série do Ensino Médio do período vespertino.

O quadro 1, apresenta resumidamente o planejamento e implementação da sequência didática desenvolvida.

Quadro 1: roteiro de implementação da sequência didática

\begin{tabular}{|c|c|c|}
\hline ATIVIDADES & TEMAS & $\begin{array}{l}\text { № DE } \\
\text { AULAS }\end{array}$ \\
\hline Atividade 01 & $\begin{array}{l}\text { Questões problema iniciais } \\
\text { Mapas conceituais iniciais (MCI) } \\
\text { Organização das equipes }\end{array}$ & 1 \\
\hline Atividade 02 & $\begin{array}{l}\text { Texto 1: Quem pinta o mundo } \\
\text { Texto 2: Ondas eletromagnéticas } \\
\text { Experimento: Blindagem eletromagnética } \\
\text { Tarefa: Pesquisa sobre os principais nomes da teoria das } \\
\text { ondas eletromagnéticas. }\end{array}$ & 2 \\
\hline Atividade 03 & $\begin{array}{l}\text { Apresentação de relatório } \\
\text { Discussão sobre a pesquisa } \\
\text { Texto 3: Espectro eletromagnético } \\
\text { Questões } \\
\text { Estudo do espectro por escala e potenciação } \\
\text { Sorteio dos Temas dos seminários }\end{array}$ & 2 \\
\hline Atividade 04 & $\begin{array}{l}\text { Construção do espectrômetro } \\
\text { Apresentação dos seminários em grupos }\end{array}$ & 2 \\
\hline Atividade 05 & $\begin{array}{l}\text { Texto 4: Radiações não ionizantes e ionizantes } \\
\text { Discussão sobre vantagens e desvantagens das radiações } \\
\text { eletromagnéticas } \\
\text { Produção de mapa conceitual em grupo } \\
\text { Produção de mapa conceitual coletivo no quadro }\end{array}$ & 2 \\
\hline Atividade 06 & $\begin{array}{l}\text { Texto 5: Maravilhas do Século XX } \\
\text { Texto 6: Raio X } \\
\text { Questionário } \\
\text { Produção de panfletos } \\
\text { Retorno a temática inicial com mapas conceituais individuais }\end{array}$ & 2 \\
\hline
\end{tabular}

Fonte: os autores

Esta investigação, de abordagem qualitativa, utilizou dois instrumentos para a coleta de dados: as questões problema, respondidas pelos alunos e o diário de campo produzido pelo pesquisador.

Essas notas de campo permitem ao pesquisador descrever os sujeitos, objetos, lugares, acontecimentos, atividades e debates. Nestas descrições o pesquisador poderá 
registrar as suas ideias, reflexões e estratégias sobre os dados de seu estudo qualitativo (BATISTA, 2016), portanto são um instrumento que pode representar todos os dados coletados durante a pesquisa.

Para análise das questões problema e das notas de campo, utilizamos os pressupostos teóricos e metodológicos de Bardin (1977) onde o seu método se baseia em categorizações por análise de conteúdo. Neste sentido, essas notas de campo serão apresentadas e discutidas nas seguintes categorias: (i) motivação para o estudo de física, (ii) trabalho em equipe e (iii) cumprimento da atividade proposta.

Para mantermos no anonimato dos sujeitos da pesquisa, foram atribuídos aos alunos nomes fictícios e por uma questão de organização, estes foram separados de acordo com os seus grupos de trabalho em sala de aula, já que estes grupos se mantiveram com os mesmos integrantes durante todo o desenvolvimento da sequência didática. Assim ficaram: grupo $A\left(A_{1}, A_{2}, A_{3}\right)$, grupo $B\left(B_{1}, B_{2}, B_{3}\right)$, grupo $C\left(C_{1}, C_{2}, C_{3}\right)$ e grupo $D\left(D_{1}, D_{2}, D_{3}, D_{4}\right)$, totalizando os 13 alunos participantes.

\section{Resultados e Discussão}

Com o intuito de verificar como os alunos se mobilizariam diante de uma proposta diferenciada de ensino, apresentaremos e analisaremos a seguir os dados obtidos pelo professor pesquisador, por meio das notas de campo que foram coletadas durante a implementação da sequência didática.

A implementação da sequência didática ocorreu entres as datas de 26/08/16 à 14/09/2016, e um fator positivo foi que nesse período não registramos nenhuma falta dos alunos envolvidos, possibilitando inferir que eles apresentaram elementos para a categoria (i), ou seja, sentiram-se motivados em participar das atividades da sequência didática, ou seja, para o estudo da física.

$\mathrm{Na}$ sequência apresentamos os relatos e os dados obtidos por notas de campo de cada um dos encontros e suas análises.

- 1ํㅡㄹ Encontro: (01 aula)

Neste encontro, solicitamos aos alunos que respondessem as questões problema iniciais e a confecção dos Mapas Conceituais Iniciais e no final da aula foi indicado dois voluntários para fazer um estudo em casa do texto "Quem pinta o mundo?" (FIGUEIREDO; PIETROCOLA, 2000) e apresentação na aula seguinte.

Quando sugerimos o tema "onda" para a confecção do mapa conceitual, surgiram vários questionamentos principalmente sobre a própria ferramenta de ensino.

Algumas notas tomadas a partir das falas iniciais são apresentadas no quadro 2 a seguir: 
Quadro 2: relatos iniciais dos alunos de acordo com as categorias

\begin{tabular}{|c|l|}
\hline Categorias & \multicolumn{1}{|c|}{ Fala dos alunos } \\
\hline (i) & $\begin{array}{l}\text { Aluno } \mathrm{B}_{3} \text { - "É aquele negócio dos quadradinho professor, mas posso escrever } \\
\text { qualquer coisa que penso mesmo sobre isso". } \\
\text { Aluno } \mathrm{C}_{2} \text { - "Mas qualquer onda faz parte da física professor, até essas do } \\
\text { celular e wi-fi". } \\
\text { Auna } \mathrm{D}_{4} \text { - "So de sabe que num vai te conta eu já gostando" }\end{array}$ \\
\hline (ii) & $\begin{array}{l}\text { Auno } \mathrm{C}_{3}-\text { "Ah já que nóis vamos fazer tudo em equipe, porque o senhor não } \\
\text { deixa isso hoje". }\end{array}$ \\
\hline (iii) & $\begin{array}{l}\text { Auna D }- \text { "Professor tem certeza que posso ponha qualquer coisa, o senhor } \\
\text { não vai rir e nem mostrar pra ninguém né". }\end{array}$ \\
\hline
\end{tabular}

Fonte: os autores

Nesta aula percebemos uma inquietação dos alunos a respeito dos trabalhos a serem desenvolvidos, principalmente em ter a correção imediata de suas respostas ou constatações, porque não estão acostumados com esse sistema em sala de aula.

Quanto as respostas do quadro 2, constatamos que mesmo sendo um momento inicial, alguns conceitos físicos começaram a surgir, juntamente com algumas aplicações tecnológicas. Nesse momento algumas indagações foram feitas ao professor pesquisador, e estas foram devolvidas aos alunos novamente em forma de uma nova pergunta, pois, nessa proposta de trabalho o professor precisa cuidar para não dar as respostas "certas", o mesmo deve gerar e mediar as discussões, os debates.

- 2ำ Encontro: (02 aulas)

Inicialmente 2 alunos fizeram a leitura e dramatização do texto "Quem pinta um mundo?" para coletar as respostas de cada uma das questões propostas na sequência didática a partir das discussões de cada equipe. Durante as discussões observamos uma boa interação nos grupos, mas, a todo o momento os alunos solicitavam a confirmação de suas respostas pelo professor, o que mostrou uma boa participação na aula de física, no entanto, um sentimento de insegurança diante dos colegas de grupo.

Em seguida solicitamos a produção de um pequeno texto sobre luz e notamos que eles a relacionavam principalmente com situações cotidianas, tais como o ato de enxergar e as cores que vemos, ambos os assuntos discutidos na série anterior, no conteúdo de óptica. Na sequência, apresentamos um vídeo curto (aproximadamente 4 minutos), cujo objetivo do mesmo era introduzir formalmente o tema "ondas eletromagnéticas". Após a apresentação desse vídeo, alunos fizeram a leitura de um texto sobre o mesmo assunto e então conseguiram estabelecer relações com as suas respostas das questões problema iniciais e com o Mapa Conceitual Inicial produzido na aula anterior. 
"Agora já vi que fiz um monte de coisa errada naquele mapinha da aula passada" (Aluno $\mathrm{B}_{2}$ ).

Percebemos na fala do aluno uma tomada de consciência sobre suas concepções espontâneas apresentadas no início do trabalho, o que de acordo com Novak e Gowin (1999) é o primeiro passo para que o processo de aprendizagem ocorra no aluno.

No término desse encontro, solicitamos que os grupos fizessem uma pesquisa sobre os principais cientistas envolvidos no desenvolvimento do tema onda eletromagnética, a fim de verificar o engajamento do aluno com o estudo da física fora do ambiente escolar, contemplando as categorias (i), (ii) e (iii) anteriormente apresentadas, pois, muitos alunos dificilmente fazem pesquisas em casa sobre temas de física, mesmo quando o professor solicita.

- 3o Encontro: (02 aulas)

Neste encontro, iniciamos os trabalhos apresentando as pesquisas sobre os principais cientistas que contribuíram para o desenvolvimento do tema ondas eletromagnéticas. Para nossa satisfação, todos os grupos apresentaram os trabalhos prontos, com nomes diferentes, mas alguns foram recorrentes como: Lenz, Faraday, Maxwell, Huygens e Hertz. Cada grupo teve um tempo para apresentar seus autores pesquisados e debater sobre o assunto, e o professor-pesquisador apenas conduziu a atividade. Verificamos com essa atividade que os alunos estavam entusiasmados com as aulas de física que segundo eles estavam diferentes das outras aulas. Talvez por esse motivo cumpriram as tarefas e produziram uma boa discussão, o que ao nosso ver contemplou as três categorias elencadas.

Em seguida propusemos a leitura do Texto 3 sobre "Espectro Eletromagnético", para responder as questões que estavam propostas no final desse texto e, orientamos que havia um texto com o mesmo nome no livro didático e, que o mesmo poderia servir de subsídio para a solução da tarefa. Após a leitura e discussão nos pequenos grupos sobre as questões propostas, explicamos na lousa, por meio de uma aula expositiva e dialogada, alguns conceitos teóricos como frequência, período, amplitude, comprimento de onda, velocidade de propagação, energia transportada pela onda e suas respectivas equações.

Quando solicitamos que respondessem as atividades propostas, percebemos mais dificuldades dos alunos nas questões argumentativas do que nas questões que necessitavam de cálculos matemáticos, demonstrando indícios de que os trabalhos na disciplina de física sempre envolveram matematização, por isso uma maior facilidade. Em seguida, fizemos os sorteios de alguns assuntos sobre as radiações para que os grupos preparassem seminários, que seriam apresentados por eles na aula seguinte e fechamos mais um encontro da sequência didática.

A partir da descrição dos encaminhamentos anteriores percebemos que as três categorias foram contempladas, verificamos elementos que motivaram o estudo da física, trabalho em equipe e principalmente um grande empenho dos alunos em cumprir com as atividades propostas. Nessa aula, uma aluna apresentou a seguinte fala: 
"Eu prefiro cálculo nas aulas, porque da bem menos trabalho do que fazer esse monte de coisa, porque não gosto de ler também"(Aluna $\left.\mathrm{B}_{2}\right)$.

Com esta fala inferimos que apesar da aluna não estar satisfeita com as atividades, ela demonstrou que $o$ ato de pensar e refletir a incomodava, ou seja, que os trabalhos estavam mexendo com suas estruturas cognitivas.

- 40 Encontro: (02 aulas)

Iniciamos esse encontro com a realização de uma atividade experimental, a construção de um espectrômetro com os materiais já preparados pelo professor. Essa atividade tinha como objetivo permitir ao aluno manusear diferentes materiais, seguir procedimentos, discutir no grupo as hipóteses levantadas e consequentemente os resultados obtidos, contemplando assim de acordo com Zabala (1999) os conteúdos conceituais, procedimentais e atitudinais.

Os alunos demostraram empenho e satisfação em realizar essa atividade experimental e, até fotografaram os resultados obtidos com a dispersão da luz branca e os utilizaram em seus perfis de rede social, o que mais uma vez corrobora com a questão da motivação do aluno para o estudo da física. Essa, de acordo com Boruchovitch e Bzuneck (2001) é uma motivação extrínseca causada pela atividade proposta e principalmente pelo ambiente de aprendizagem gerado com a sequência didática.

Em seguida foram apresentados os seminários, e todos os alunos participantes realizaram essa atividade em seus respectivos grupos, alguns com maior profundidade e afinco na explicação do tema, outros nem tanto. Percebemos uma organização satisfatória das equipes em relação a essa atividade, o que mostrou inferência para a categoria (ii), pois teve senso de trabalho em grupo, divisão de tarefas e comprometimento durante a apresentação.

Durante as apresentações fizemos algumas contribuições e até correções de erros nas falas e conteúdos, porém enaltecemos a organização dos alunos e procuramos motivar o trabalho em equipe. Nessas inferências aproveitamos para conduzir um diálogo sobre as radiações ionizantes e não ionizantes e constatamos que nas apresentações, os grupos focaram principalmente na história da descoberta das radiações, saúde, bem estar social e comunicação, o que vai ao encontro do enfoque em CTS.

Nesse sentido, constatamos que as apresentações dos grupos estavam focadas em uma física aplicável em situações dos seus cotidianos, em seus riscos e benefícios, evidenciando a dimensão social do conhecimento científico e tecnológico, e que vai ao encontro do proposto por Pinheiro; Silveira; Bazzo (2007, p. 73).

Como as apresentações se estenderam um pouco além do planejado, parte das atividades deste encontro foram postergadas para aula seguinte e que ao final da implementação da sequência necessitamos de mais uma aula, que a princípio seriam 10 e na verdade foram 11 para vencer todo o planejamento. 
Nesse encontro realizamos uma discussão sobre os perigos das radiações ionizantes para o dia-a-dia das pessoas, para isso cada uma das equipes apresentou os seus argumentos a partir de estudos realizados em casa. Em seguida os alunos assistiram um documentário sobre a vida de Marie Curie e qual foi a sua importância no contexto científico de sua contemporaneidade e, para estudos posteriores no campo das radiações. Foi interessante quando uma aluna apresentou a seguinte fala:

"Nossa para uma mulher fazer essas coisas ela deve ter enfrentado muitos problemas né prof., porque a gente num vê se falar de mulher que foi grande cientista, acho que da física foi a primeira, porque eu só lembro de nome de homem" (Aluna $A_{1}$ ).

Percebemos com essa fala que a aluna traz em seus pensamentos uma série de indagações e que antes não havia se dado conta, o que entendemos como indícios referentes à categoria (i).

Em seguida orientamos que os alunos fizessem a leitura nos seus pequenos grupos do texto: "Maravilhas do Século", a fim de discutir e responder as questões referentes ao mesmo. Então propusemos que cada equipe construísse novamente um mapa conceitual a fim de propor o dialogo sobre o tema no grupo e principalmente familiarizar os mesmos com o processo de elaboração de mapas conceituais. Foi um momento muito interessante, pois, percebemos por meio das falas dos alunos que aquele conceito não poderia ser ali, porque ele era ligado com um outro e dai por diante. Essas conversas permitiram inferir elementos referentes em todas as categorias, pois constatamos um maior aprofundamento cognitivo dos alunos e uma maior motivação para a realização das tarefas.

"Essa radiação não é ionizante, lembra que vimos que ela vibra menos que luz que nós enxergamos" (Aluna $\mathrm{D}_{4}$ ).

Ao realizar essa fala, a aluna apresentou elementos de conhecimento físico de frequência, espectro, energia, o que mostra uma predisposição para entender os próximos conceitos físicos.

Em outro relato uma aluna fez o seguinte comentário:

Eu gostei prof. desses mapas, agora eu tô usando ele pra fazer resumos pra estudar pra provas de outras matérias, fica bem mais fácil de ver as coisas pra entender" (Aluna $D_{1}$ ).

Percebe-se com essa fala que a estratégia desenvolvida durante a sequência didática tornou-se viável para além das aulas de física, e que permitiu a aluna encaminhar seu próprio método de estudo, o que consideramos ser o primeiro passo para uma participação ativa no processo de ensino e aprendizagem.

Próximo ao fim desta aula, propomos a elaboração de um mapa conceitual coletivo na lousa, sobre a mesma temática do produzido anteriormente pelos grupos. Foi um momento em que rapidamente o quadro ficou cheio de conceitos e muitas contribuições 
foram dadas quanto à posição dos mesmos na estrutura dos mapas conceituais, demonstrando que não há um método único e nem correto de fazer mapas conceituais, mas que cada um constrói o seu de acordo sua estrutura cognitiva (MOREIRA, 2012; MOREIRA; MASINI, 2001; NOVAK; GOWIN, 1999).

- 6ํㅡㄹ Encontro: (02 aulas)

Iniciamos os trabalhos mais uma vez em grupo lendo um texto sobre Raios $X$ produzido pelo pesquisador para em seguida responder algumas questões problema. Para auxiliar as discussões foram apresentados três vídeos curtos que também tratavam sobre o assunto dos Raios X.

Nas discussões para a formulação das respostas presenciamos muitos questionamentos a respeito dos conceitos físicos, o que indicou uma pré-disposição para categoria (i), pois falavam em grande fonte de energia, profundidade de penetração das radiações ionizantes, o porquê que nas chapas radiográficas os ossos apareciam claros e os tecidos moles não.

"Eu acho que os Raios X não passam porque eles são fracos, não atravessando os ossos, só as partes de carnes"...."mas como é que se usa eles pra ver dento de motores ou nos aeroportos, aquele lá são mais fortes professor? Ou é uma outra espécie de raios" (Aluno C2).

Com essa fala, percebemos que o aluno apresentou elementos de conhecimento satisfatório sobre a energia das radiações ionizantes, que o levam a estender seus pensamentos além do conteúdo conceitual que estava sendo ministrado. Esse relato ainda nos forneceu indícios de que os alunos começaram a relacionar o conteúdo de física com aplicações tecnológicas, o que é satisfatório uma vez que a maioria dos alunos acreditavam que a física era um emanherado de "fórmulas".

Ao término desse encontro, os alunos produziram individualmente um novo mapa conceitual sobre o tema ondas, a fim de organizar suas ideias sobre os conteúdos discutidos durante a aplicação da sequência didática.

\section{Considerações Finais}

Entendemos que o compromisso com uma educação plena deva buscar o equilíbrio entre os conhecimentos úteis para a vida cotidiana e àqueles que conjuntamente levam a uma visão ampla das ciências, permitindo uma inclusão verdadeira, que atenda todas as especificidades dos alunos, para que os mesmos venham exercer a sua cidadania completa, nesta sociedade que está em constante evolução.

Com o desenvolvimento da sequência didática, percebemos que, os indícios de aprendizagem apresentados pelos sujeitos pesquisados se deram a partir da motivação dos alunos e do professor pelo ambiente de aprendizagem estabelecido e pelo assunto abordado. Essa motivação pode advir a partir da associação entre teoria, prática e 
aplicação cotidiana, com conteúdos voltados para a vivência dos educandos. Nesse sentido, a perspectiva ciência, tecnologia e sociedade (CTS), se apresentou como um bom viés para o favorecimento de um ensino potencialmente significativo.

Por meio das análises das falas tomadas nas notas de campo verificamos uma motivação para o cumprimento de todas as atividades, organização dos trabalhos em equipe e predisposição para estudar os conteúdos de física. Podemos aqui inferir, que a única mudança no contexto escolar nesse período foi a postura do professor com relação à turma, nessa proposta de sequência didática o aluno se tornou um participante ativo da aula interagindo todo o tempo com seu pequeno grupo, com os demais grupos e com o professor e, a postura do professor foi de facilitador, de mediador dos debates.

Alguns poucos alunos ofereceram certa resistência inicial a aplicação da sequência didática, visto que estavam acostumados com um ensino tradicional, alegando que preferiam fazer contas. Essa postura foi superada com o decorrer das aulas, pois os mesmos quando se deram conta estavam apresentando seminários e discutindo suas ideias nos pequenos grupos.

Diante das análises realizadas, consideramos que a implementação da sequência didática devidamente planejada e estruturada com diferentes recursos de ensino e sob uma perspectiva das relações CTS, gerou um ambiente de aprendizagem completamente diferente do tradicionalmente adotado por muitos professores, permitindo assim que os alunos num estágio de motivação se tornassem corresponsáveis pelo processo de ensino e aprendizagem.

Assim, constatamos que a sequência didática aplicada pode ser considerada como um material potencialmente significativo, podendo ser indicada como um bom recurso didático aos professores que se interessarem em ministrar aulas diferentes das convencionais. Nesse sentido, espera-se que esse trabalho possa estimular outros professores a pensarem um ensino de física diferente, criando e produzindo outros materiais potencialmente significativos, capazes de tornar a física uma disciplina menos temida e seu ensino mais prazeroso.

\section{Referências}

ANGOTTI, J. A. P.; AUTH, M. A.. Ciência e Tecnologia: implicações sociais e o papel da Educação. Revista Ciência \& Educação. V. 7, no 1, p. 15-27, 2001.

AULER, D.. Interações entre ciência-tecnologia-sociedade no contexto da formação de professores de ciências. Tese de Doutorado. 2002, 257f. Tese ( Doutorado em Educação: Ensino de Ciências Naturais) - Universidade Federal de Santa Catarina, Florianópolis, 2002.

AZEVEDO, R. O. M. et. al. O enfoque na formação de professores de ciências e a abordagem de questões sociocientíficas, In: IX ENCONTRO NACIONAL DE PESQUISA EM EDUCAÇÃO EM CIÊNCIAS - IX ENPEC, Águas de Lindóia/SP, 2013, Atas..., São Paulo: $2013 . \quad<$ Disponível em: http://www.nutes.ufr.br/abrapec/ixenpec/atas/resumos/R0325-1.pdf acesso em: 04/12/2016>. 
BARDIN, L.. Análise de conteúdo. Trad. Luís Antero Reto e Augusto Pinheiro. Rio de Janeiro: Edições 70, 1977.

BATISTA, M. C.. Um estudo sobre o ensino de astronomia na formação inicial de professores dos anos iniciais. Tese de Doutorado. 2016, 183f.Tese (Doutorado em Educação para a Ciência e a Matemática) - Universidade Estadual de Maringá, Maringá, 2016.

BONADIMAM, H.; NONENMACHER, S. E. B.. O gostar e o aprender no ensino de física: uma proposta metodológica. Caderno Brasileiro de Ensino de Física: vol. 24, oㅡ 2, p.194-223, 2007. <Disponível em: http://dialnet.unirioja.es/descarga/articulo/5165466.pdf Acesso em: 23/11/2015>.

BORUCHOVITCH, E.; BZUNECK, J. A. (orgs.). A motivação do aluno: contribuições da psicologia contemporânea. $3^{\underline{a}}$ ed. Petrópolis: Vozes, 2001

BRASIL. Ministério da Educação (MEC), Secretaria de Educação Básica. Formação de Professores do ensino médio, Etapa II - Caderno III: Ciências da Natureza. Curitiba: UFPR/ Setor da Educação, 2014.

FREIRE, P.. Pedagogia da Esperança: um reencontro com a pedagogia do oprimido. $7^{\text {a }}$ ed. Rio de Janeiro: Paz e Terra, 1992.

FIGUEIREDO, A; PIETROCOLA, M.. Luz e Cores. São Paulo: FTD, 2000.

MOREIRA, M. A.. O que é afinal aprendizagem significativa. Aula inaugural do Programa de Pós-Graduação em Ensino de Ciências Naturais - Instituto de Física Universidade Federal do Mato Grosso. Cuiabá- MT. 2010. Aceito para publicação, Qurriculum, La Laguna, Espanha, 2012.

MOREIRA, M. A.; MASINI, E. F. S.. Aprendizagem significativa: a teoria de David Ausubel. São Paulo: Centauro, 2001.

NOVAK, J. D.; GOWIN, B.. Aprender a aprender. Lisboa: Plátano, 1999.

PINHEIRO, N. A. M.; SILVEIRA, R. M. C. F.; BAZZO, W. A.. Ciência, tecnologia e sociedade: a relevância do enfoque CTS para o contexto do ensino médio. Revista Ciência \& Educação. V. 13, № 1, p. 71-84, 2007.

RESQUETTE, S.O.. Uma sequência didática para o ensino da radioatividade no nível médio, com enfoque na história e filosofia da ciência e no movimento cts. Tese de Doutorado. 2013, 281f. Tese (Doutorado em Educação para a Ciência e a Matemática) Universidade Estadual de Maringá, Maringá, 2013.

ROSA, C. W da; ROSA, A. B. da.. O Ensino de Ciências (Física) no Brasil: da história às novas orientações Educacionais. Revista Ibero-americana. № 58/2, 24 p. 2012. $<$ Disponível

em:

https://www.google.com.br/?gws_rd=ssl\#q=Situa\%C3\%A7\%C3\%A30+atual+do+ensino+d e+f\%C3\%ADsica+no+brasil > acesso 18/06/2016.

SANCHES, M. B.; Neves, M. C. D. S.. A Física moderna e contemporânea no ensino médio: uma reflexão didática. Maringá: Eduem, 2011. 
SANTOS, W. L. P. dos.. Contextualização no ensino de ciências por meio de temas CTS em uma perspectiva crítica. Revista Ciência \& Ensino. V. 1, número especial de 2007.

SANTOS, W. L. P.; MORTIMER, E. F.. Uma análise de pressupostos teóricos da abordagem C-T-S (Ciência- Tecnologia - Sociedade) no contexto da educação brasileira. Revista Ensaio Pesquisa em Educação em Ciências. V. 2, oㅡ 2, p. 110-132, dez, 2000.

SENRA, C. P.. Uma proposta para enriquecer o ensino de física: os projetos de pesquisa e a abordagem cts. 2011.Dissertação de Mestrado. Dissertação (Mestrado em Ensino de Ciências e Matemática) - Centro Federal de Educação Tecnológica Celso Suckow da Fonseca - CEFET/RJ, Rio de Janeiro, 2011. Disponível em: <https://www.google.com.br/?gws_rd=ssl\#q=Situa\%C3\%A7\%C3\%A3o+atual+do+ensino+ de+f\%C3\%ADsica+no+brasil: acesso em 10/09/2016.

ZABALA, A. A prática educativa: como ensinar. Porto Alegre: ArtMed, 1998.

Submissão: 26/12/2016

Aceite: 22/03/2017 